\title{
LUT
}

University

\section{Applying a multi-objective optimization approach in designing water supply systems for mining industries. The case of Chile}

Herrera Sebastián, Lucay Freddy, Cisternas Luis, Kraslawski Andrzej

This is a Post-print

version of a publication

published by Elsevier

in Journal of Cleaner Production

DOI: $\quad$ 10.1016/j.jclepro.2018.11.081

Copyright of the original publication: (c) 2018 Elsevier Ltd.

Please cite the publication as follows:

Sebastián Herrera-León, Freddy A. Lucay, Luis A. Cisternas, Andrzej Kraslawski, Applying a multi-objective optimization approach in designing water supply systems for mining industries.

The case of Chile, Journal of Cleaner Production (2018), doi: 10.1016/j.jclepro.2018.11.081

This is a parallel published version of an original publication.

This version can differ from the original published article. 


\section{Accepted Manuscript}

Applying a multi-objective optimization approach in designing water supply systems for mining industries. The case of Chile

Sebastián Herrera-León, Freddy A. Lucay, Luis A. Cisternas, Andrzej Kraslawski

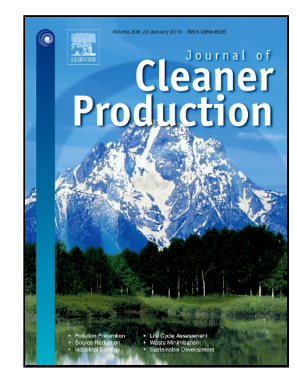

PII:

S0959-6526(18)33484-X

DOI:

10.1016/j.jclepro.2018.11.081

Reference:

JCLP 14840

To appear in:

Journal of Cleaner Production

Received Date:

28 May 2018

Accepted Date:

08 November 2018

Please cite this article as: Sebastián Herrera-León, Freddy A. Lucay, Luis A. Cisternas, Andrzej Kraslawski, Applying a multi-objective optimization approach in designing water supply systems for mining industries. The case of Chile, Journal of Cleaner Production (2018), doi: 10.1016/j.jclepro. 2018.11.081

This is a PDF file of an unedited manuscript that has been accepted for publication. As a service to our customers we are providing this early version of the manuscript. The manuscript will undergo copyediting, typesetting, and review of the resulting proof before it is published in its final form. Please note that during the production process errors may be discovered which could affect the content, and all legal disclaimers that apply to the journal pertain. 


\title{
Applying a multi-objective optimization approach in designing water supply systems for mining industries. The case of Chile
}

Sebastián Herrera-León ${ }^{1,2,3, *}$, Freddy A. Lucay², Luis A. Cisternas ${ }^{2,3}$, Andrzej Kraslawski ${ }^{1,4}$

${ }^{1}$ LUT School of Engineering Science, Lappeenranta University of Technology, Finland

${ }^{2}$ Departamento de Ingeniería Química y Procesos de Minerales, Universidad de Antofagasta, Chile

${ }^{3}$ Centro de Investigación Científico Tecnológico para la Minería, CICITEM, Chile

${ }^{4}$ Department of Process and Environmental Engineering, Lodz University of Technology, Poland

*Corresponding author: sebastian.herrera@lut.fi; sebahleon@gmail.com

\begin{abstract}
This work presents a multi-objective optimization approach to designing integrated water supply systems for the mining industry. The main goal is to estimate the total operational costs and greenhouse gas emissions from water supply systems. Chilean mining industry has been selected as a case study because of acute problem of water scarcity that it experiences. The current strategy to face the problem applied by the mining companies operating in Chile consists in building independent water supply systems that use ocean as the source of water. This solution is highly energy intensive, which is why the problem of water consumption is also a problem of energy consumption. The proposed optimization approach determines - from technical, economic and environmental perspective - the optimal topology of the system, optimal locations and sizes of water treatment plants, pumping stations, and pipelines. In addition, the analysis takes into account the eventual use of photovoltaic solar system in order to decrease greenhouse gas emissions. Our main findings have demonstrated that an integrated water supply system is always the best option from an economic and environmental point of view.
\end{abstract}

Keywords: mining industry; Chile; integrated water supply; desalination; solar energy 


\section{Introduction}

Water is an essential resource for the mining industry, required in different quantity and quality in all production stages. Mining companies usually get water from the surrounding areas, generating in some cases local conflicts with other users who use water from the same source (Wessman et al., 2014). This becomes a serious problem, which jeopardizes their social license to operate generating financial risks for mining business (Urkidi, 2010; Zhang et al., 2015). Water management is a key activity to face this issue and the research literature provides methods for its developing in the mining context. However, these methods address mainly operational issues of water use, not the strategic aspects of water management (Côte et al., 2010; Gunson et al., 2010; Gunson et al., 2012). It means that the efforts have been focused on efficient use of water in mining operations rather than on addressing problems and conflicts with local communities and the environment. In this context, the integrated water resources management has been proposed as an approach to address strategic aspects of the use of water. The first step in this approach is to define the quantity of available water (Kunz et al., 2013; Kunz and Moran, 2014). The mining industry gets water from different sources depending on the local circumstances; its common sources are: surface water, groundwater, and seawater (Northey et al., 2016). The problem of water management in mining operations is especially acute in the arid and semi-arid areas. That was our major motivation to focus on water resources management in the arid regions of Chile.

Chile is known as a mining country as it is a producer and exporter of valuable metals and minerals, such as copper, lithium, potassium, gold, silver, molybdenum, nitrates and iodine (Cisternas and Galvéz, 2014). Mining sector generates significant economic benefits but also creates environmental footprints related mainly to water and energy consumption (Lagos et al., 2018). The majority of mining operations take place at the Atacama Desert, the driest desert on earth (Clarke, 2006). Therefore, water is obtained from fossil aquifers since other sources are almost non-existent (Aitken et al., 2016). However, gradually water resources in this area have been overexploited and historical water balance has been negative since 1996 (Valdés-Pineda et al., 2014). It was the reason why the Chilean government decided to stop issuing new water withdrawal rights from any aquifers to any user located in this area (Rivera et al., 2016). Therefore, new mining projects or mining expansion projects have limited options of getting access to water. These possibilities include: purchasing water withdrawal rights from other users; transporting water from another region; or withdrawing water directly from the ocean. From among those 
possibilities, mining companies have seen the ocean as the best option to get water (Ghorbani and Kuan, 2017).

There are mines that use seawater directly in their operations (Moreno et al, 2011). Nevertheless, the decision to this end must be taken in initial phases of the project since seawater could interfere with some processes and affect the lifetime of facilities (Liu et al., 2013; Jeldres et al., 2016). To avoid these problems, new mines that are already in operation or in the planning phase have included a Reverse Osmosis (RO) plant as the option to desalinate seawater to eliminate harmful contaminants and excess of ions. (Chilean Copper Commission, 2016a). This decision has important economic consequences as installation and operation of a RO plant entails high costs (Ghaffour et al., 2013). However, in this type of water supply system, the most essential aspect from economic and technical perspective is not the seawater desalination but water conveyance.

Water conveyance is complex since mining operations are located at high altitudes and long distances from the coast (Cisternas and Gálvez, 2018). Therefore, several technical challenges must be taken into account during the phase of system design, and a significant investment is required to build and operate such a system. Due to the above mentioned conditions, water conveyance is a power-hungry process. Zhou and Tol (2005) indicate that conveying water vertically for a distance of 100 meters requires the same energy as conveying it horizontally for a distance of $100 \mathrm{~km}$. It is clear that electricity consumption to convey the desalinated water to mining sites is enormous as some mining operations are located over 3000 meters above the sea level. In Chilean industry the problem of water supply is becoming a problem of energy consumption as energy is consumed mostly in the form of electricity (Ihle and Kracht, 2018). Energy comes predominantly from the combustion of fossil fuels, which generates large quantities of greenhouse gases (GHG) (Joo et al, 2015). However, the Atacama Desert offers an excellent opportunity to use solar energy (Haas et al., 2018). Therefore, solar technologies could be crucial for decreasing GHG emissions and enabling cleaner production of minerals and metals in Chile (Moreno-Leiva et al., 2017; Pamparana et al., 2017). 


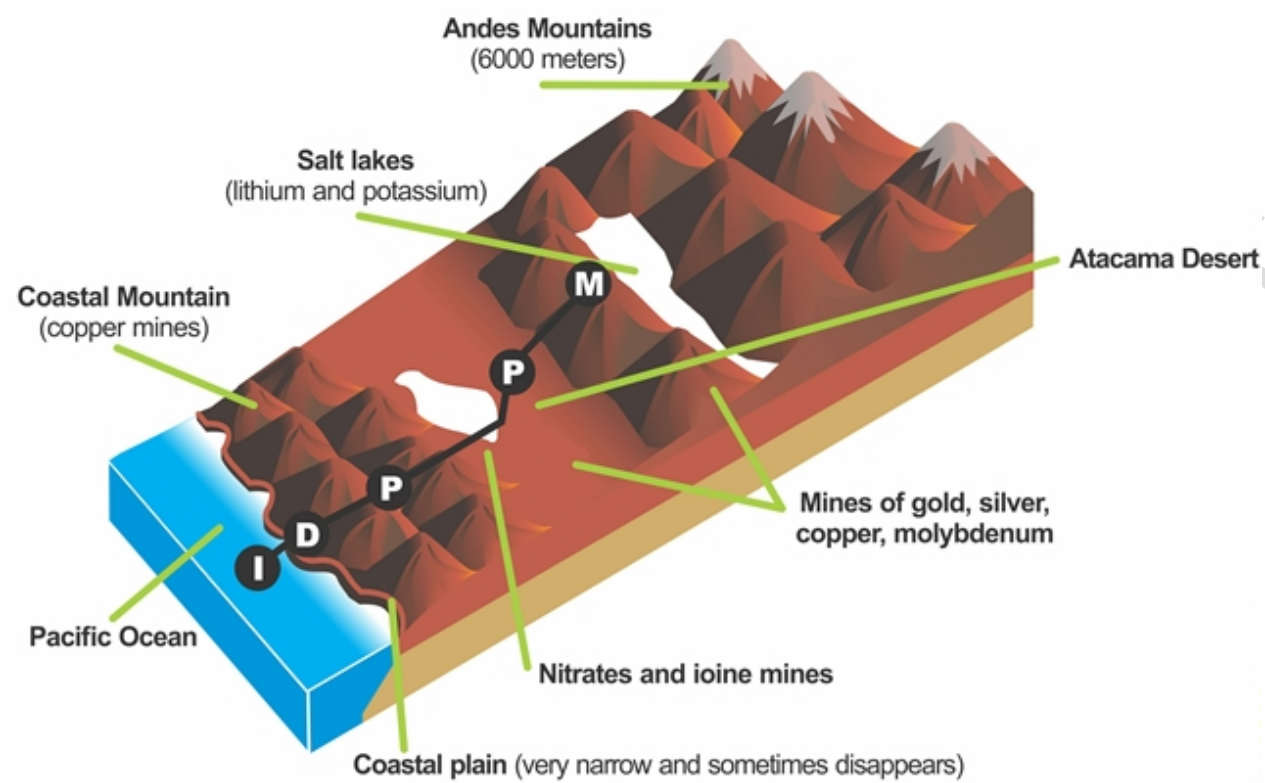

Fig. 1: Conceptual geographical scheme of the Atacama Desert (Cisternas and Gálvez, 2018)

Fig. 1 shows Atacama Desert to illustrate its topography and a typical water supply system used in mining operations. The system consists of a seawater intake facility (I), an RO plant (D), a set of pumping stations $(\mathrm{P})$ and long pipelines to convey water to the location of mining operation (M). In this context, the water supply system varies according to water demand, the mining operation location, the piece of land available to install the desalination plant and the location of where pumping stations and pipelines will be installed. At present, mines have been independently carrying out their water supply projects, without considering the option of sharing infrastructure with other mining companies, other industries or regional water supply services. It is due to several factors, such as coordination of implementation time between different projects, business risks entailed by sharing infrastructure, and potential conflicts between users that could occur over the access to water (Dixon, 2013). The reductionist strategy currently applied by mining companies helps avoid these problems but from a holistic and systemic perspective, shared infrastructure could be a better solution for all users who participate in the project. Shared infrastructure should ensure the reduction of energy consumption, and decrease the installation costs of the RO plant and the water supply system, as they are dependent on the economy of scale.

In this work, we present a multi-objective optimization approach to designing an integrated water supply system for the mining industry. We estimate the total cost of such a system and GHG 
emitted during its operation. We have chosen Chile as our case study and because of the environmental conditions of Atacama Desert the design methodology includes the option to select a photovoltaic solar system (PV system) as one of the sources of energy demanded by the water supply system. The optimization model determines technical, economic and environmental aspects of: the optimal topology of the system; optimal locations and sizes of RO plants, pumping stations, and pipelines; and the size of the PV system. The optimization approach was developed in order to answer the following research questions:

- Is an integrated water supply system the best option from the economic and environmental point of view for mining companies?

- What are the total costs of an integrated water supply system?

- What is the quantity of GHG emissions related to the water supply system operation?

- Is it technically and economically feasible to include a PV system in the integrated water supply system?

- What is the quantity of GHG emissions eliminated if the PV system is included?

\section{Methods}

The design problem consists in determining the optimal water supply system that satisfies the demand for desalinated water of several mining operations. The system is expected to identify the location and size of RO plants and pumping stations, the size of PV system, as well as the length and diameter of pipelines. To find this optimal solution, water supply system is presented as a network including nodes and arcs. Nodes represent desalination plants, pumping stations, and mining operations, while arcs represent the pipelines. The network includes all feasible water supply alternatives and is defined using a geographic information system (GIS), which allows identifying the specific locations and elevations of RO plants, pumping stations, and mining operations, as well as the length of pipelines between nodes. In this work, the trade-off between economic and environmental aspects of the system is assessed. The economic aspects are represented by the total costs of the system, while environmental aspects are represented by the GHG emissions resulting from the system energy consumption. The weighted sum method is used to assess the trade-off, in which both objectives are aggregated to a single one through 
normalization. It is worth to mention that the proposed optimization method does not consider the use of contaminated water originating from the same and/or other users, as well as the influence of climate change on the availability of water resources. These topics have been addressed by Gao and collaborators (Gao et al., 2014; Gao et al, 2016; Gao et al., 2017).

The multi-objective optimization model, as well as its validation and application to a realscale case study, are described in the next subsections.

\subsection{Optimization model}

Four main sets are used in the model: the set of RO plants, $\mathrm{SO}=\{$ so $\mid$ so is an RO plant $\}$, the set of pumping stations $\mathrm{N}=\{\mathrm{n} \mid \mathrm{n}$ is a pumping station $\}$, the set of mining operations $\mathrm{SI}=\{\mathrm{si} \mid \mathrm{si}$ is a mining operation $\}$, and the set of pipe diameters $\mathrm{D}=\{\mathrm{d} \mid \mathrm{d}$ is a pipe diameter $\}$. The potential connections between two nodes $i, j$ are established in the set $F I J$, with defined distances $\left(L_{i, j}\right)$ and altitude differences $\left(\Delta Z_{i, j}\right)$ between each other. By knowing potential connections, we also know water flow inlets and outlets for each node represented respectively by sets input and output.

For each node of the network, flow conservation constraints based on the continuity equation ensure that water flows produced or introduced into a node are equal to water flows consumed or extracted at the same node. Flow conservation in the desalination plants, pumping stations and mining operations are described in Eq. (1), Eq. (2) and Eq. (3) respectively. The maximum production capacity of each RO plant $\left(C_{s o}^{\max }\right)$ and water requirements set by each mining operation $\left(R_{s i}\right)$ are described in Eq. (4) and Eq. (5) respectively.

Eq. (1)

$$
Q_{\text {so }}=\sum_{n \in \text { output }} Q_{s o, n} \quad \forall s o \in S O
$$

Eq. (2)

$$
\sum_{i \in \text { input }} Q_{i, n}=\sum_{j \in \text { output }} Q_{n, j} \quad \forall n \in N
$$

Eq. (3) 


$$
Q_{s i}=\sum_{n \in \text { input }} Q_{n, s i} \quad \forall s i \in S I
$$

Eq. (4)

$$
Q_{\text {so }} \leq C_{\text {so }}^{\max } \quad \forall s o \in S O
$$

Eq. (5)

$$
Q_{s i} \geq R_{s i} \quad \forall s i \in S I
$$

Since each RO plant must have an adjacent pumping station, pipelines exist just between pumping stations and between pumping stations and mining operations. For the selection of pipeline diameter between nodes $n$ and $j$ we use Eq. (6) and Eq. (7). The binary variable $y_{n, j, d}$ is included in the model to select only one of the available diameters, while the binary variable $y_{n, j}$ to evaluate the existence of a pipeline between nodes $n$ and $j$. If the binary variable $y_{n, j}$ is zero, there is no pipeline between node $n$ and $j$.

Eq. (6)

$$
\sum_{d \in D} y_{n, j, d}^{\prime}=y_{n, j} \quad \forall(n, j) \in F I J
$$

Eq. (7)

$$
D_{n, j}=\sum_{d \in D} D_{d} \cdot y_{n, j, d}^{\prime} \quad \forall(n, j) \in F I J
$$

Maximum velocity $\left(v^{\max }\right)$ of water flowing into pipelines is a relevant criterion in the design of a water supply system. This parameter must not exceed a specific value to avoid a number of potential operating problems, for instance, the flow-assisted corrosion problem. Because velocity is a parameter and not an explicit variable, the maximum velocity is expressed as a bounded function of the water flow by using the relationship between velocity and pipeline area, as described in Eq. (8). Based on the information given by Voutchkov (2013), the maximum linear velocity considered in this optimization model is $2.5 \mathrm{~m} / \mathrm{s}$.

Eq. (8) 


$$
Q_{n, j} \leq \frac{\pi \cdot D_{n, j}^{2}}{4} \cdot v^{\max } \quad \forall(n, j) \in F I J
$$

The energy equation expressed in the Eq. (9) is fundamental for pipelines. This equation results in $H_{i, j}$ that is the pressure value known as the hydraulic head, expressed in terms of the column of water. The $\Delta Z_{i, j}$ is the altitude difference between node $i$ and node $\mathrm{j}, H_{\mathrm{j}}$ is the pressure in the terminal node $j$, and $h_{i, j}$ is the pressure loss in the pipeline caused by friction. The so-called Darcy-Weibach equation (Swamee and Sharma, 2008) expressed in Eq. (10) is used to describe the pressure loss in the pipelines. In order to simplify the design problem, the Darcy friction factor $(f)$ of 0.03 was considered as constant in the optimization model. The gravitational acceleration ( $g$ ) is $9.8 \mathrm{~m} / \mathrm{s}^{2}$ while the pressure in the terminal node is $0 \mathrm{~m}$ under the assumption that every node receiving water has a storage tank exposed to the environment. A new continuous variable $\left(D Y_{n, j}\right)$, dependent on the binary variable $y_{n, j}$, is included as described in Eq. (11) to avoid discontinuity when the chosen diameter is zero. Then, if the binary variable $y_{n, j}$ is zero (no pipeline), it is logical that the new continuous variable is also zero.

Eq. (9)

$$
H_{n, j}=\Delta Z_{n, j}+H_{j}+h_{n, j} \quad \forall(n, j) \in F I J
$$

Eq. (10)

$$
h_{n, j}=D Y_{n, j} \cdot \frac{8 \cdot f \cdot L_{n, j} \cdot Q_{n, j}{ }^{2}}{\pi^{2} \cdot g} \quad \forall(n, j) \in F I J
$$

Eq. (11)

$$
D Y_{n, j} \cdot D_{n, j}^{5}=y_{n, j} \quad \forall(n, j) \in F I J
$$

The power $\left(P_{n}\right)$ required by each pumping station is expressed in Eq. (12) and is a function of water flow discharged by the pumps and the hydraulic head. The mass density of water $(\rho)$ considered in this model is $1000 \mathrm{~kg} / \mathrm{m}^{3}$ while the combined efficiency of the pump and prime $\operatorname{mover}(\eta)$ is $80 \%$.

Eq. (12) 


$$
P_{n}=\frac{\rho \cdot g}{\eta} \cdot \sum_{j \in \text { output }} Q_{n, j} \cdot H_{n, j} \quad \forall n \in N
$$

The annual electricity required by each RO plant $\left(E N E_{s o}\right)$ is a function of its capacity and the unitary electrical energy consumption of each RO plant $(U N C)$ that is expressed in Eq. (13). Considering data given by Shahabi et al. (2017), the electrical energy consumption of an RO plant is $3.1 \mathrm{kWh} / \mathrm{m}^{3}$.

Eq. (13)

$$
E N E_{\text {so }}=U N C \cdot Q_{\text {so }} \quad \forall s o \in S O
$$

The annual electricity required by each pumping station $\left(E N E_{n}\right)$ is a function of its power and the number of hours when the system is active throughout the year $(T)$, which is expressed in Eq. (14). The number of operating hours per year for the system is $8,760 \mathrm{~h} / \mathrm{y}$. This assumption implies no downtime for maintenance of the system that is required in practice. However, from the design perspective, we assume that the system is going to operate during all year without interruptions. This is done in order to calculate the maximum total costs of the water supply system and the maximum quantity of greenhouse gases emitted.

Eq. (14)

$$
E N E_{n}=T \cdot P_{n} \quad \forall n \in N
$$

Eq. (15) expresses the total annual electricity required by the water supply system (TE), which is the sum of the annual electricity required by all RO plants and all pumping stations selected to be part of the project.

Eq. (15)

$$
T E=\sum_{s o \in S O} E N E_{s o}+\sum_{n \in N} E N E_{n}
$$

The total annual electricity required by the water supply system can be supplied directly by the Chilean power grid (CE) combined with electricity generated by the newly constructed PV system (SE), as expressed in Eq. (16). The new PV system is limited by the performance ratio ( $P R)$, its capacity in standard conditions $(P P)$, the local irradiance $(I R R)$, the irradiance in standard conditions $\left(I R R^{*}\right)$, and the number of days per year that the system is operating $(T T)$, as expressed 
in Eq. (17). The performance ratio determines how effectively a PV system converts sunlight into electricity, and although it varies according to local weather conditions, in this optimization model a fixed value is considered. According to data reported by Fuentealba et al. (2015) and Hass et al. (2018), a performance ratio of $50 \%$ and a local irradiance of $6 \mathrm{kWh} / \mathrm{m}^{2} \mathrm{~d}$ are used. The number of operating days per year for the system is $365 \mathrm{~d} / \mathrm{y}$ and the irradiance in standard conditions is $1 \mathrm{kWh} / \mathrm{m}^{2}$. To restrict its size to logical conditions, the capacity of the PV system is limited by the total power required for RO plants and pumping stations to operate within a determined time as is expressed in Eq. (18). To supply the electricity generated in $100 \%$ by solar energy, an installation of a system of batteries is required. However, other technical aspects must be also addressed, e.g., type and capacity of the batteries and loss of battery efficiency. However, those factors are out of the scope of our work.

Eq. (16)

$$
T E=C E+S E
$$

Eq. (17)

$$
S E=T T \cdot P R \cdot P P \cdot \frac{I R R}{I R R^{*}}
$$

Eq. (18)

$$
P R \cdot P P \leq \sum_{s o \in S O} U N C^{*} \cdot Q_{s o}+\sum_{n \in N} P_{n}
$$

The annualized capital cost of RO plants $\left(\mathrm{CECSO}_{s o}\right)$ expressed in MUS\$/y is described in Eq. (19). The value of the parameters $\alpha$ and $\beta$ is -41963 and 399694 respectively, and both were adjusted using the data given by Shahabi et al. (2017). However, these parameters can be interchanged for future works depending on the information available. To be consistent with the work developed by Shahabi et al. (2017), a discount rate ( $d r)$ of $6.62 \%$ and an investment period (year) of 20 years were considered for evaluating the water supply projects.

Eq. (19) 


$$
\operatorname{CECSO}_{\text {so }}=\frac{\alpha \cdot Q_{\text {so }}{ }^{2}+\beta \cdot Q_{\text {so }}}{\frac{(1+d r)^{\text {year }}-1}{d r \cdot(1+d r)^{\text {year }}}} \quad \forall s o \in S O
$$

The annualized capital cost of pumping stations $\left(C E C N_{n}\right)$ and the annualized capital costs of pipelines $\left(\operatorname{CECP}_{n, j}\right)$ expressed in MUS\$/y are described in Eq. (20) and Eq. (21) respectively. The value of the parameter $k_{n}$ considered in the model is $4.94 \mathrm{MUS} \$ \mathrm{~kW}$ and was adjusted with the information obtained from Samra and Abood (2014). While the values of the parameters $\sigma, \theta$ and $\vartheta$ are respectively $-702.93,4881.7$ and 3024.3, which were adjusted with the data obtained from Shahabi et al. (2017). Eq. (22) describes the annualized capital cost of the PV system (CECSP ) expressed in MUS $\$ / y$. The value of the parameter $k_{S}$ considered in the model is $1.2 \mathrm{MUS} \$ / \mathrm{kW}$, which was adjusted with the information obtained from International Renewable Energy Agency (2018).

Eq. (20)

$$
\operatorname{CECN}_{n}=\frac{k_{n} \cdot P_{n}}{\frac{(1+d r)^{\text {year }}-1}{d r \cdot(1+d r)^{\text {year }}}} \quad \forall n \in N
$$

Eq. (21)

$$
\operatorname{CECP}_{n, j}=\frac{L_{n, j} \cdot\left(\sigma \cdot D_{n, j}{ }^{3} \cdot \theta \cdot D_{n, j}{ }^{2} \cdot \vartheta \cdot D_{n, j}\right)}{\frac{(1+d r)^{\text {year }}-1}{d r \cdot(1+d r)^{\text {year }}}} \quad \forall(n, j) \in F I J
$$

Eq. (22)

$$
\operatorname{CECSP}=\frac{k_{s} \cdot P P}{\frac{(1+d r)^{\text {year }}-1}{d r \cdot(1+d r)^{\text {year }}}}
$$

Eq. (23) describes the operational cost of RO plants $\left(\mathrm{OECSO}_{s o}\right)$ expressed in MUS\$/y, which is composed of a variable and fixed cost. The amount $0.4 \mathrm{US} \$ \mathrm{~m}^{3}$ is considered the fixed cost (FIX) that represents membrane replacements, labor, chemical reagents and miscellaneous 
(Gude, 2016). Variable cost is a function of electricity required by RO plant and the electricity cost $(E C)$ that is $0.1 \mathrm{US} \$ / \mathrm{kWh}$. The relation $(C E / T E)$ represents the contribution of electricity supplied by the power grid. Eq. (24) describes the operational cost of pumping stations $\left(O E C N_{n}\right)$ expressed in MUS\$/y that is the function of the electricity required by pumping stations and the electricity cost. Eq. (25) represents the operational cost of the PV system (OECSP). The value of the parameter $k_{S}^{*}$ in the model is $0.05 \mathrm{MUS} \$ \mathrm{~kW}$, which was adjusted with the data obtained from International Renewable Energy Agency (2018).

Eq. (23)

$$
O_{E C S O}=\left(\frac{C E}{T E}\right) \cdot E C \cdot E N E_{s o}+F I X \cdot Q_{s o} \quad \forall s o \in S O
$$

Eq. (24)

$$
\operatorname{OECN}_{n}=\left(\frac{C E}{T E}\right) \cdot E C \cdot E N E_{n} \quad \forall n \in N
$$

Eq. (25)

$$
O E C S P=k_{S}^{*} \cdot P P
$$

The annual total cost of the system (TC) expressed in MUS\$/y is described in Eq. (26). The total cost includes annualized capital and operational costs of RO plants, pumping stations, pipelines, and PV system. Annual GHG emissions caused by the water supply system operation ( $G H G)$ are described in Eq. (27). GHG emissions are a function of electricity consumed by the system during its operation and are expressed in $\mathrm{kt}^{\mathrm{CO}_{2 \mathrm{eq}}} \mathrm{y}$. The annual GHG emissions are computed using average GHG emission rates estimated by Shrestha et al. (2011). Further, GHG emissions vary depending upon the type of energy source therefore they are calculated for individual sources of the Chilean power grid (National Energy Commission of Chile, 2015). The current interconnection of Chile's two main power grids (Central Interconnected System, SIC, and Northern Interconnected System, SING) is considered in the optimization model. The data used for estimating GHG emissions are shown in Table 1. Based on this data the unitary GHG emissions by the Chilean power grid (UNE) are $542.74 \mathrm{~g} \mathrm{CO}_{2 \mathrm{eq}} / \mathrm{kWh}$, while the unitary GHG emissions by the PV system (UNESP) amount to $1.42 \mathrm{~g} \mathrm{CO}_{2 \mathrm{eq}} / \mathrm{kWh}$. 
Eq. (26)

$$
T C=\sum_{s o \in S O} C E C S O_{s o}+\sum_{n \in N} C E C N_{n}+\sum_{n, j \in F I J} C E C P_{n, j}+C E C S P+\sum_{s o \in S O} O E C S O_{s o}+\sum_{n \in N} O E C N_{n}+O E C S P
$$

Eq. (27)

$$
G H G=C E \cdot U N E+S E \cdot U N E S P
$$

Table 1: Estimated GHG emissions of the Chilean power grid

\begin{tabular}{|c|c|c|c|}
\hline $\begin{array}{c}\text { Energy } \\
\text { source by } \\
\text { type }\end{array}$ & $\begin{array}{c}\text { Chilean power } \\
\text { grid } \\
{[\%]}\end{array}$ & $\begin{array}{c}\text { GHG emission rates } \\
\text { reported in Shrestha et al. } \\
(2011) \\
{\left[\mathrm{g} \mathrm{CO}_{2 \mathrm{eq}} / \mathrm{kWh}\right]}\end{array}$ & $\begin{array}{c}\text { GHG emissions rates by } \\
\text { power generation in } \\
\text { Chile } \\
{\left[\mathrm{g} \mathrm{CO}_{2 \mathrm{eq}} / \mathrm{kWh}\right]}\end{array}$ \\
\hline Coal & 40 & 1023 & 409.20 \\
\hline Hydroelectric & 33 & 25 & 8.25 \\
\hline Natural gas & 16 & 606 & 96.96 \\
\hline Biomass & 3 & 86 & 2.58 \\
\hline Oil & 3 & 780 & 23.40 \\
\hline Wind & 3 & 31 & 0.93 \\
\hline Solar $(\mathrm{PV})$ & 2 & 71 & 1.42 \\
\hline
\end{tabular}

The weighted sum method is utilized to assess the trade-off between the economic and environmental aspects of the water supply system described in Eq. (26) and Eq. (27). This method allows aggregating several functions to a single one through normalization, since functions frequently have different unit measures. In this exercise, we used the normalization approach called upper-lower bound approach (Marler and Arora, 2005), for which we need to know the upper and lower limits of each function. Weighted sum method is known as an a priori method since it requires ex-ante information about decision-makers' preferences to be translated into weights before optimization takes place (Marler and Arora, 2010). For each normalized function a weight $\left(w_{i}\right)$ has to be chosen, and the sum of all weights must be equal to one $\left(\sum_{i=1}^{k} w_{i}=1\right)$. By varying the weights, based on decision-makers' preferences, different solutions can be reached for the design problem. The multi-objective function (MOF) is expressed in Eq. (29), while Eq. (28) describes the sum of weights. The lower bound of the annual total cost of the system $\left(T C^{L O W}\right)$ and the upper bound of the annual GHG emissions $\left(G H G^{U P}\right)$ are set up by minimization of the Eq. (26), 
while the upper bound of the annual total cost of the system $\left(T C^{U P}\right)$ and the lower bound of the annual GHG emissions $\left(G H G^{L O W}\right)$ are found by the minimization of Eq. (27).

Eq. (28)

$$
w_{1}+w_{2}=1
$$

Eq. (29)

$$
M O F=w_{1} \cdot \frac{T C-T C^{L O W}}{T C^{U P}-T C^{L O W}}+w_{2} \cdot \frac{G H G-G H G^{L O W}}{G H G^{U P}-G H G^{L O W}}
$$

Based on previous works (Herrera et al., 2015; Herrera-León et al., 2018), we know that the convergence time in similar cases increases with the scale and complexity. Seeing the complexity level in terms of the number of equations and nonlinear elements included in them, the optimization model proposed in the present work can be regarded as complex. Furthermore, the model is expected to be a useful and efficient tool for decision-makers, therefore it must be capable to solve real-scale design problems within a short time. To achieve this goal and in order to improve the computational efficiency of the proposed optimization model, nonlinear functions of Eq. (12), Eq. (19) and Eq. (21) were linearized using a piecewise method. The piecewise method is described in detail in the work of Lin et al. (2013) and its foundations are briefly explained below. In the words of Lin et al. (2013), most commonly used textbooks on nonlinear programming approximate the nonlinear function by a piecewise linear function as follows. Firstly, denote $a_{k}$ $(k=0,1, \ldots, m)$ as the break points of a nonlinear continuous function $f(x)$ that satisfy the condition $a_{0}<a_{1}<\ldots<a_{m}$. Then, $f(x)$ can be approximately linearized over interval $\left[a_{0}, a_{m}\right]$ as $L(f(x))$ $=\sum_{k=0}^{m} f\left(a_{k}\right) \cdot t_{k}$ where $x=\sum_{k=0}^{m} a_{k} \cdot t_{k}, \Sigma_{k=0}^{m} t_{k}=1, t_{k} \geq 0$, in which only two adjacent $t_{k}$ 's are allowed to be nonzero.

In summary, the water supply system is represented as a mixed integer nonlinear programming (MINLP) problem described by Eqs. (1)-(28) and Eq. (29) as the multi-objective function that includes the economic and environmental aspects of the system.

\subsection{Optimization model validation}

A real water supply project for a Chilean mining operation was evaluated in order to contrast the information provided by technical reports and publications with results obtained using 
the proposed optimization model. A new project of the National Copper Corporation of Chile was selected, which aims to meet the water demand required for the copper sulphide ores processing of Radomiro Tomic (RT) mining operation located at 3000 meters above sea level. Chilean government approved the project on 20.01.2016, whose full description can be found in http://seia.sea.gob.cl/documentos/documento.php?idDocumento=8210094. The water supply system is composed of an RO plant producing a maximum of $1965 \mathrm{l} / \mathrm{s}$, five pumping stations and a 48 -inch pipeline $160 \mathrm{~km}$ long. Fig. 2 shows a conceptual representation of the project location and Fig. 3 a conceptual representation of its topography.

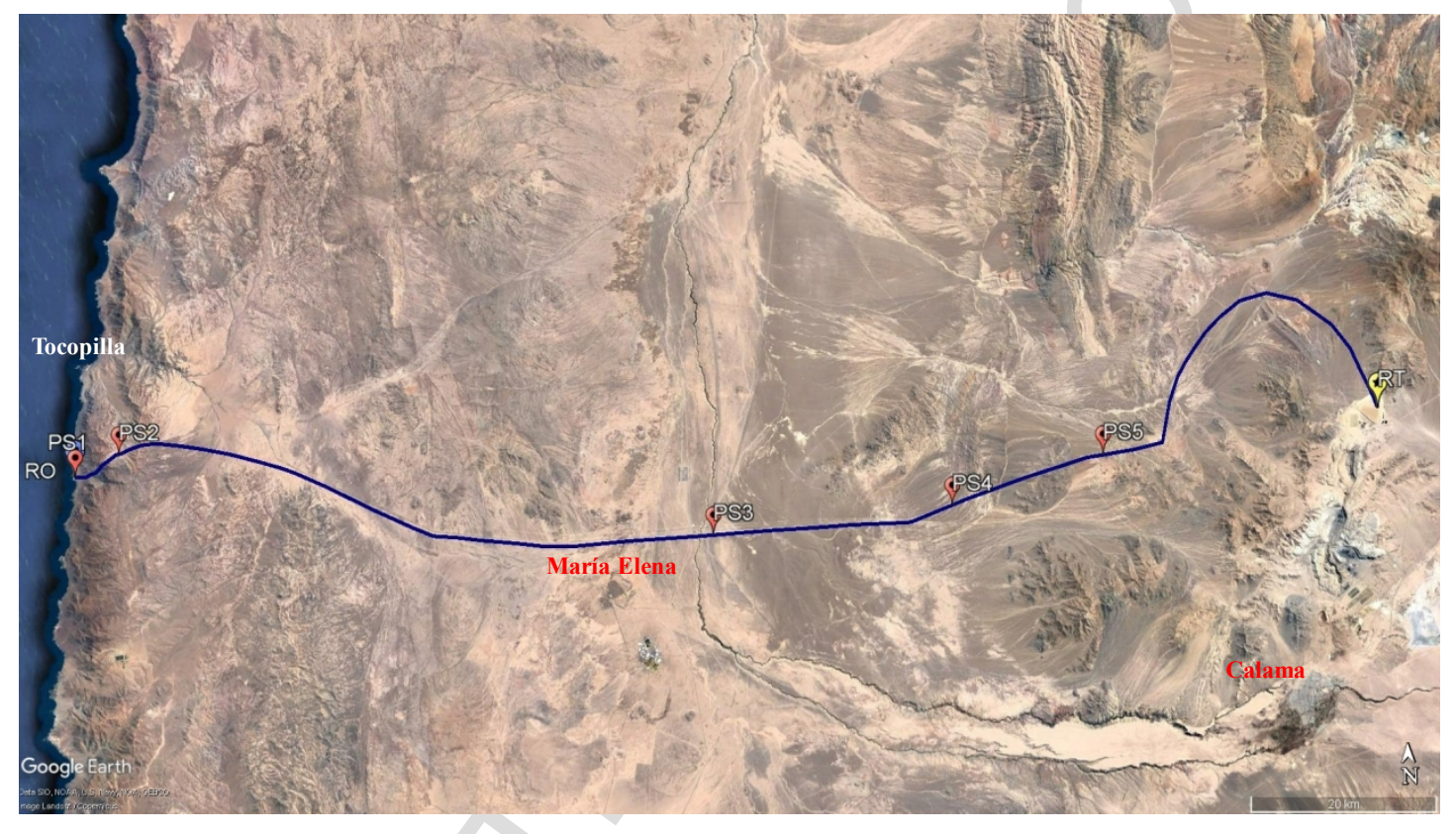

Fig. 2: Conceptual representation of water supply system for RT mining operation 


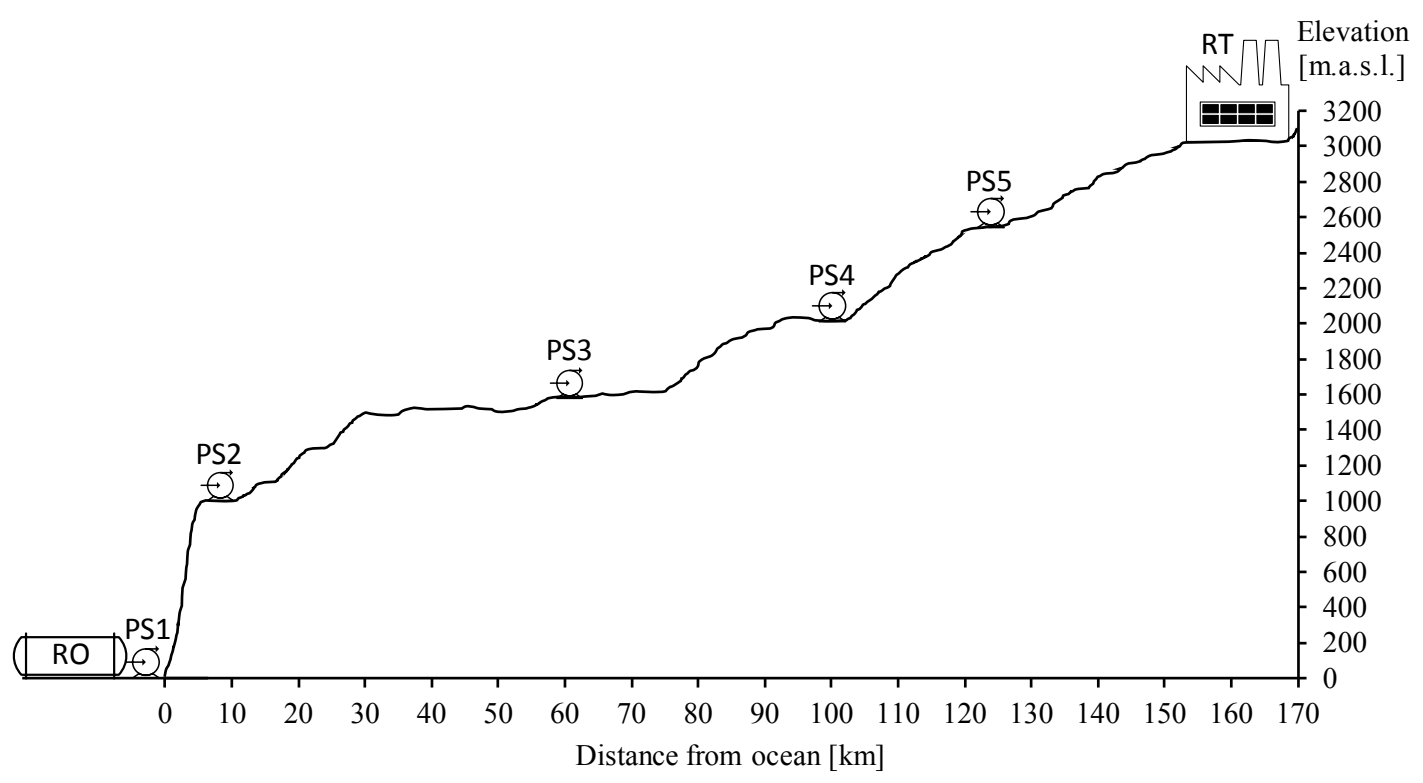

Fig. 3: Conceptual representation of the water supply system topography for RT mining operation

When minimizing the total cost of the system using Eq. (26) as the objective function, we obtained the cost of the RO plant of $1.61 \mathrm{US} \$ / \mathrm{m}^{3}$ and the cost of the conveyance system (pumping stations and pipelines) of $3.04 \mathrm{US} \$ \mathrm{~m}^{3}$. The Chilean National Productivity Commission (2017) reported that for a typical copper mining operation located at 3400 meters above sea level the total cost of the project is approximately $5.1 \mathrm{US} \$ / \mathrm{m} 3$, broken down by the RO plant $-1.5 \mathrm{US} \$ / \mathrm{m}^{3}$ and the conveyance system - 3.6 US\$ $/ \mathrm{m}^{3}$. Taking this into consideration, the results obtained from the optimization model are correct, and slight variations in the costs can be attributed to the mining operation location as well as to optimization model assumptions such as electricity price and discount rate. The results obtained did not include a PV system, obtaining the energy required by the water supply system directly from Chilean energy grid. In this context, the GHG emissions were minimized using Eq. (27) as the objective function of the optimization model in order to evaluate other solutions. The new solution proposes a PV system the capacity of $270.37 \mathrm{MW}$ at the cost of $0.15 \mathrm{US} \$ \mathrm{kWh}$, which is similar to data reported in the literature (Fuentealba et al., 2015; IRENA, 2018). As a result, the cost of RO plant decreases to $1.54 \mathrm{US} \$ / \mathrm{m}^{3}$ comparing with the first solution and the cost of a conveyance system to $2.64 \mathrm{US} \$ / \mathrm{m}^{3}$. However, we need to include 
a new cost of the PV system of $0.7 \mathrm{US} \$ / \mathrm{m}^{3}$. Therefore, the total cost increases from $4.65 \mathrm{US} \$ / \mathrm{m}^{3}$ to $4.87 \mathrm{US} \$ / \mathrm{m}^{3}$, while the $\mathrm{GHG}$ emissions decrease from $643.06 \mathrm{kt} \mathrm{CO}_{2 \mathrm{eq}} / \mathrm{y}$ to $482.71 \mathrm{kt} \mathrm{CO}_{2 \mathrm{eq}} / \mathrm{y}$.

\subsection{Case study}

In Chile, the Atacama Desert comprises the regions of Arica and Parinacota, Tarapaca, Antofagasta, Atacama and the north part of Coquimbo (Fig. 4). The case study focuses on the region of Antofagasta, which is the second largest in the country in terms of the surface area and with the highest concentration of mining projects. The region is famous for the reserves and production of lithium, nitrates, silver, gold, and copper among others, which account for more than $60 \%$ of the regional gross domestic product (Chilean Copper Commission, 2013). However, the mining sector is also the largest regional consumer of water and energy, $60 \%$ and $90 \%$, respectively (Meza et al., 2015). The overall average water runoff availability in the region is $52 \mathrm{~m}^{3} /$ hab/year (Valdés-Pineda et al., 2014), which is very close to the limit of the minimum water requirement estimated for human health and for economic and social development that is $49.28 \mathrm{~m}^{3} / \mathrm{hab} /$ year (Chenoweth, 2008). 


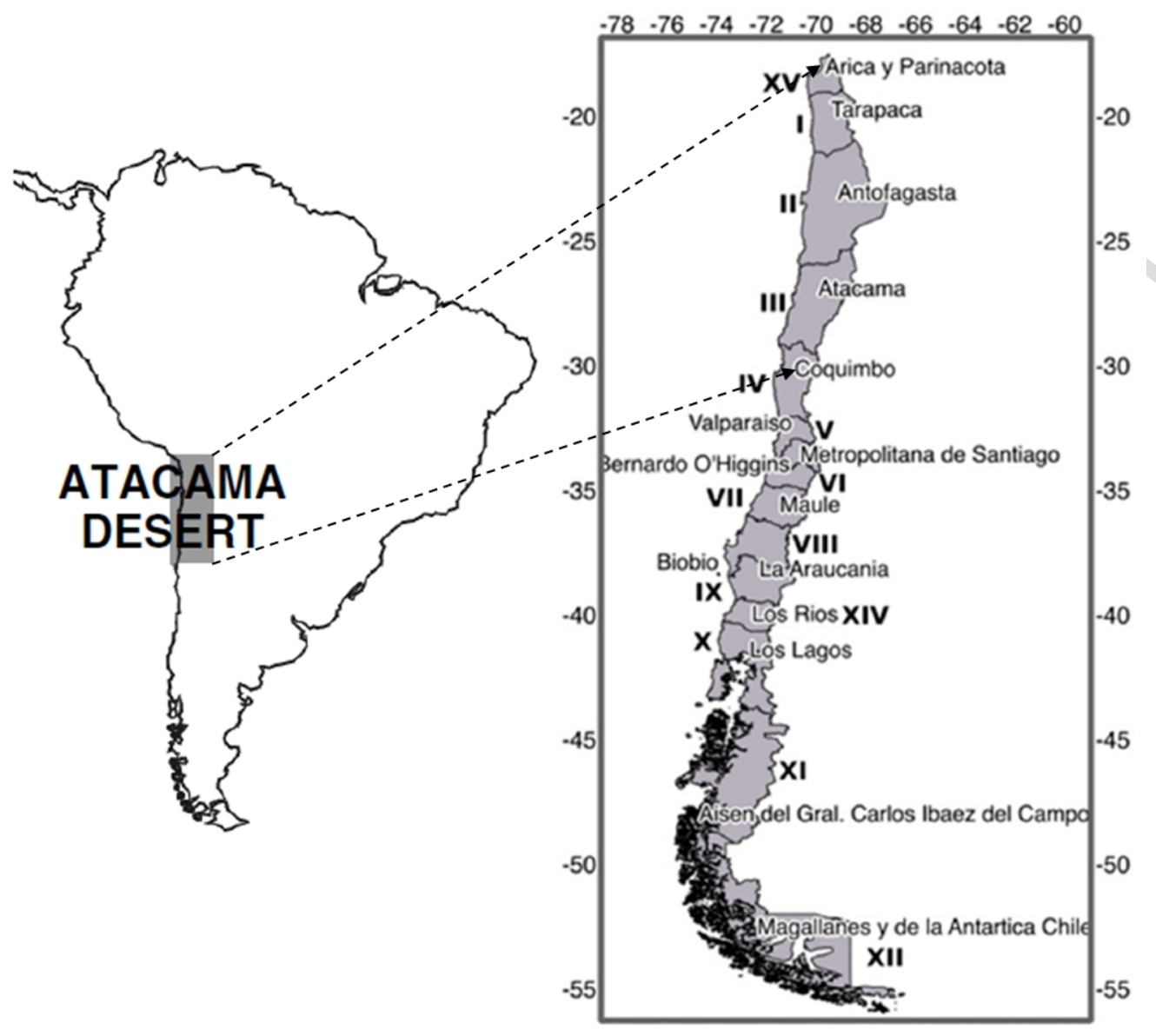

Fig. 4: Atacama Desert location (adapted from Aitken et.al, 2016 and Houston, 2006)

In this context, RO plants have been installed in the region and other desalination projects are under evaluation in order to satisfy the increasing water demand of the mining sector. Table 2 shows the water supply projects for Chilean mining operations (Chilean Copper Commission, 2016b), where it is possible to monitor projects located in the Antofagasta region. In addition, $60 \%$ of the drinking water supplied to the city of Antofagasta (capital of the region) that has ca. 400000 inhabitants is based on desalinated water. The RO plant called "La Chimba" has been in operation since 2003 and currently a new desalination project has been approved by the Chilean Government to supply the remaining $40 \%$ of the city. Following this decision, Antofagasta city will be the first city in South America supplied 100\% with desalinated water. Therefore, there are several desalination projects in the region but an integrated water supply system such as the one shown below has not been assessed. 
Table 2: Desalination projects for Chilean mining operations (adapted from Chilean Copper Commission, 2016b)

\begin{tabular}{|c|c|c|c|c|}
\hline $\begin{array}{c}\text { Mining } \\
\text { Company }\end{array}$ & $\begin{array}{c}\text { Mining } \\
\text { Operation }\end{array}$ & Region & $\begin{array}{c}\text { Project } \\
\text { phase }\end{array}$ & $\begin{array}{c}\text { Capacity } \\
{[\mathbf{l} / \mathbf{s}]}\end{array}$ \\
\hline Pampa Camarones & Pampa Camarones & Arica y Parinacota & In operation & 12,5 \\
\hline BHP Billiton & Escondida & Antofagasta & In operation & 525 \\
\hline Lunding Mining & Candelaria & Atacama & In operation & $300-500$ \\
\hline Mantos Copper & Mantoverde & Atacama & In operation & 120 \\
\hline BHP Billiton & Escondida & Antofagasta & In operation & 2500 \\
\hline CODELCO-Chile & Radomiro Tomic & Antofagasta & In construction & 1630 \\
\hline Antofagasta Minerals & Los Pelambres & Coquimbo & In evaluation & 400 \\
\hline Lunding Mining & Candelaria & Atacama & In evaluation & 500 \\
\hline BHP Billiton & Spence & Antofagasta & In evaluation & $800-1600$ \\
\hline Andes Iron SpA & Dominga & Coquimbo & In evaluation & 450 \\
\hline Mantos Copper & Mantoverde & Atacama & In evaluation & 380 \\
\hline Teck & Quebrada Blanca & Tarapacá & In evaluation & 1300 \\
\hline
\end{tabular}

The case study addressed in this work is shown in Fig. 5, in which the MO indicators represent mining operations, RO indicators represent RO plants, PS indicators the pumping stations, and the blue lines represent the pipelines. Moreover, the distances between each element of the network (RO plants, pumping stations, and mining operations) and their elevation above sea level are also shown. The case study considers three mining operations located close to the cities of Maria Elena, Calama, and Sierra Gorda. Water demand of each mining operation is 900, 1000 and $1100 \mathrm{l} / \mathrm{s}$ respectively. The potential RO plants were located in the cities of Tocopilla, Mejillones, and Antofagasta. However, the pipelines were located on paths available in the region, and the pumping stations have been installed at distances not longer than $100 \mathrm{~km}$ or at altitude differences not higher than 700 meters. For pipelines, due to commercial availability, three sizes were selected: $48^{\prime \prime}(\sim 1.22 \mathrm{~m}), 54 "(\sim 1.37 \mathrm{~m})$, and 66" $(\sim 1.68 \mathrm{~m})$. The water demand of mining operations was established based on data from the Chilean Copper Commission (2016a) related to the production of copper by processing copper sulfide minerals, which needs $0.52 \mathrm{~m}^{3}$ of water per ton of processed ore. Therefore, knowing the quantity of ore processed in each mining operation, we can calculate the demand for water. We need to stress that although our case study focuses on the copper industry, optimization approach can be adapted to any mining industry.

Another aspect that was evaluated in the case study is the water demand of cities neighboring the mining installations, which we incorporated into the system. Demand for water 
represented by cities and local communities was established based on the number of people living in each location. We assumed that on average every person uses $200 \mathrm{l} / \mathrm{d}$ while for smaller communities minimum water demand was assumed to be $100 \mathrm{l} / \mathrm{s}$. Based on these assumptions, the water demand increased to 1000, 1400 and 1200 1/s for the cities such as Maria Elena, Calama, and Sierra Gorda, respectively.

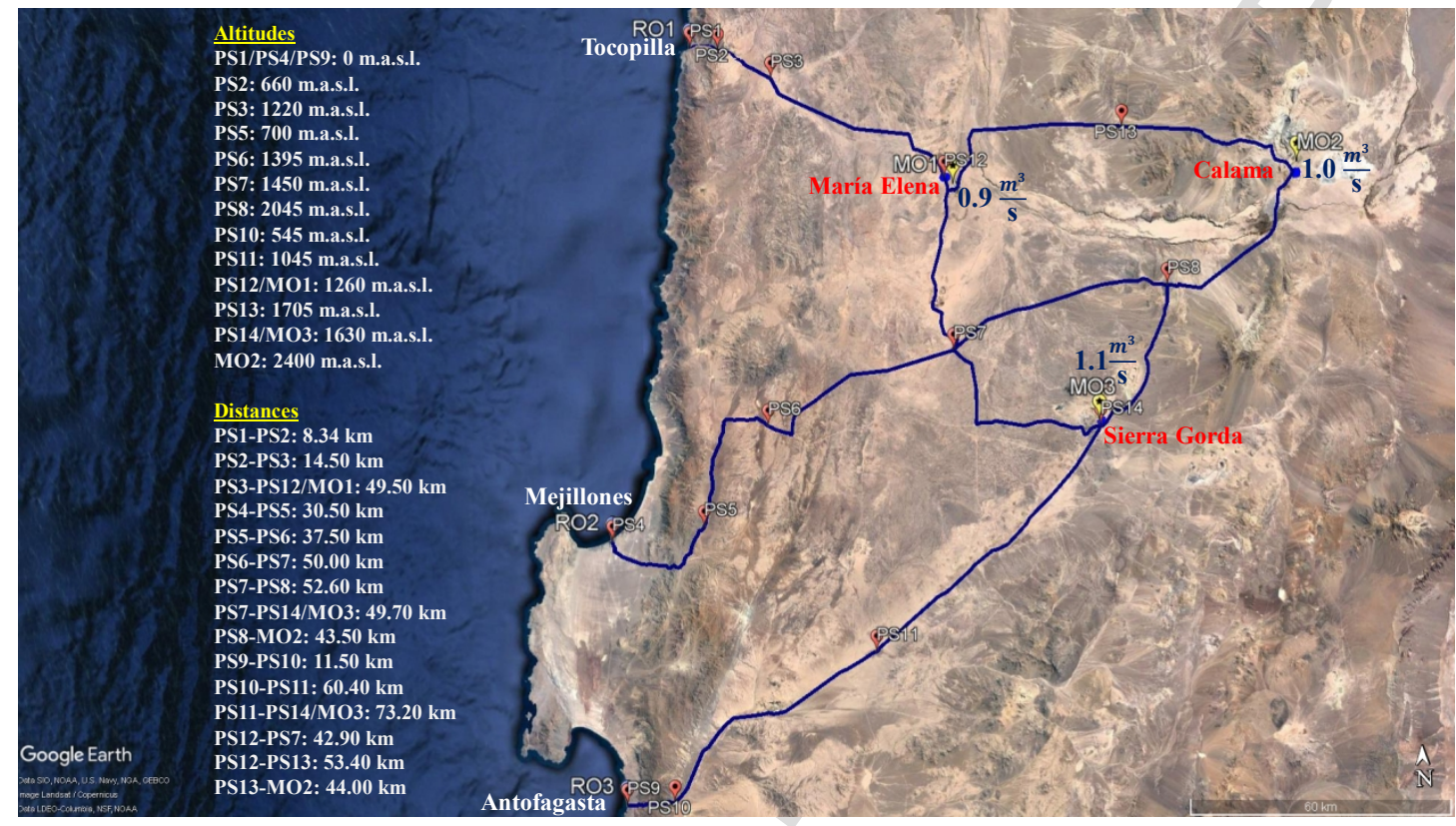

Fig. 5: Case study

\section{Results and Discussions}

Optimal solutions for the case study were obtained using the Branch-And-Reduce Optimization Navigator (BARON) in GAMS environment (GAMS, 2014), and all were obtained in less than 60 seconds. The main results shown in Tables 3 and 4 and Fig. 6 were obtained by varying the weights of the multi-objective function expressed in Eq. (29). The variations of weights were made to assess the trade-off between economic and environmental aspects of the system. Table 3 shows the costs per cubic meter of water for the three mining operations, while Table 4 tells us what happens if we incorporate cities into the system. Fig. 6 shows the annual total costs of the system and the GHG emissions for each solution, in which the Pareto front is delineated. This behavior was expected due to the multi-objective method used to address the problem (Jakob and Blume, 2014). 
As we can see from results shown in Tables 3 and 4, incorporation of the cities decreases the unitary costs of each element of the system, showing clearly its economy of scale dependency. In both cases, when economic aspects of the system were the priority, it means when $w_{1}=1$, the solution obtained was an integrated system as is shown in Fig 7. The same integrated system is maintained between points $\mathrm{A}$ to $\mathrm{B}$ and $\mathrm{H}$ to I, shown in Fig 6. After these points, the network started to change selecting even the complete network provided in the case study (Fig 5), three RO plants and fourteen pumping stations, when $w_{1}=0.1$. Although the network changes according to the variation of the weights, an integrated system is always the selected solution. Therefore, an independent system is not considered as the best option, from economic or environmental perspective.

The annual total costs of the system and GHG emissions related to its operation increase when the size of the system increases as shown in Fig. 6. For instance, when cities are incorporated in the design exercise, the Pareto front moves to the right and the total costs increase by $19.8 \%$ and the GHG emissions by $32.7 \%$ when $w_{1}=1$ (comparing points $\mathrm{A}$ and $\mathrm{H}$ ). This difference begins to decrease when the environmental aspects take more relevance. For instance, when $w_{1}$ $=0$ the total costs increase by $10.1 \%$ and the GHG emissions by $23.6 \%$ (points $\mathrm{G}$ and $\mathrm{M}$ ). Therefore, the incorporation of cities generates negative economic and environmental impacts but from a social perspective it also decreases conflicts over access to water.

The incorporation of a PV system is not the best option from an economic perspective. However, when environmental aspects are considered, a PV system is always included as part of the water supply system. For the integrated system shown in Fig 7, it is remarkable to indicate that when PV system the capacity of $240 \mathrm{MW}$ is included in the water supply system for mining operations, the GHG emissions decrease to $24.9 \%$ and the total cost increases just by $3.6 \%$ (from point A to B). According to these results, the marginal cost of the GHG emissions abatement is 85.03 US\$ $/ \mathrm{CO}_{2 \mathrm{eq}}$. The situation is similar when neighboring cities are considered. In this context, it is technically and economically feasible to include a PV system to considerably decrease the GHG emissions from the water supply system.

The obtained results indicate that an integrated water supply system is the best option. However, a strategic business model to carry out this type of project needs to be established. 
Considering these projects involve the construction of a large infrastructure and could participate users from the private and public sector. The public-private partnership business model might be used as an effective approach (Shen et al., 2016). However, the real benefits and related risks need to be assessed in a more detailed way.

Table 3: Water supply system costs for three mining operations

\begin{tabular}{|c|c|c|c|c|c|c|}
\hline \multicolumn{2}{|c|}{ Weights } & \multirow{2}{*}{$\begin{array}{c}\text { RO plants } \\
{\left[\mathrm{US} \$ / \mathrm{m}^{3}\right]}\end{array}$} & \multirow{2}{*}{\begin{tabular}{|c} 
Conveyance \\
{$\left[\mathrm{US} \$ / \mathrm{m}^{3}\right]$}
\end{tabular}} & \multirow{2}{*}{$\begin{array}{c}\text { PV system } \\
{\left[\mathrm{US} \$ \mathrm{~m}^{3}\right]}\end{array}$} & \multirow{2}{*}{\begin{tabular}{|c|} 
Total \\
{$\left[\mathrm{US} \$ / \mathrm{m}^{3}\right]$}
\end{tabular}} & \multirow{2}{*}{\begin{tabular}{|c|} 
Fig. 6 \\
position
\end{tabular}} \\
\hline w1 & w2 & & & & & \\
\hline 1 & 0 & 1.50 & 2.04 & 0.00 & 3.53 & $\mathrm{~A}$ \\
\hline 0.9 & 0.1 & 1.42 & 1.84 & 0.41 & 3.66 & $\mathrm{~B}$ \\
\hline 0.8 & 0.2 & 1.42 & 1.84 & 0.41 & 3.66 & B \\
\hline 0.7 & 0.3 & 1.42 & 1.84 & 0.41 & 3.66 & B \\
\hline 0.6 & 0.4 & 1.42 & 1.84 & 0.41 & 3.66 & B \\
\hline 0.5 & 0.5 & 1.61 & 1.88 & 0.38 & 3.87 & $\mathrm{C}$ \\
\hline 0.4 & 0.6 & 1.61 & 2.11 & 0.36 & 4.08 & $\mathrm{D}$ \\
\hline 0.3 & 0.7 & 1.61 & 2.27 & 0.35 & 4.23 & $\mathrm{E}$ \\
\hline 0.2 & 0.8 & 1.61 & 2.27 & 0.35 & 4.23 & $E$ \\
\hline 0.1 & 0.9 & 1.75 & 2.78 & 0.34 & 4.87 & $F$ \\
\hline 0 & 1 & 1.74 & 3.62 & 0.34 & 5.70 & G \\
\hline
\end{tabular}

Table 4: Costs of the water supply system for three mining operations and the neighboring cities

\begin{tabular}{|c|c|c|c|c|c|c|}
\hline \multicolumn{2}{|c|}{ Weights } & RO plants & Conveyance & PV system \\
{$\left[\mathrm{US} \$ / \mathrm{m}^{3}\right]$} & $\begin{array}{c}\text { Total } \\
{\left[\mathrm{US} \$ / \mathrm{m}^{3}\right]}\end{array}$ & $\begin{array}{c}\text { Fig. 6 } \\
{\left[\mathrm{US} \$ / \mathrm{m}^{3}\right]}\end{array}$ & {$\left[\mathrm{US} \$ / \mathrm{m}^{3}\right]$} & position \\
\hline 1 & 0 & 1.45 & 2.08 & 0.00 & 3.53 & $\mathrm{H}$ \\
\hline 0.9 & 0.1 & 1.45 & 2.08 & 0.00 & 3.53 & $\mathrm{H}$ \\
\hline 0.8 & 0.2 & 1.37 & 1.85 & 0.45 & 3.67 & $\mathrm{I}$ \\
\hline 0.7 & 0.3 & 1.37 & 1.85 & 0.45 & 3.67 & $\mathrm{I}$ \\
\hline 0.6 & 0.4 & 1.56 & 1.92 & 0.39 & 3.87 & $\mathrm{~J}$ \\
\hline 0.5 & 0.5 & 1.56 & 1.92 & 0.39 & 3.87 & $\mathrm{~J}$ \\
\hline 0.4 & 0.6 & 1.56 & 2.09 & 0.37 & 4.02 & $\mathrm{~K}$ \\
\hline 0.3 & 0.7 & 1.56 & 2.09 & 0.37 & 4.02 & $\mathrm{~K}$ \\
\hline 0.2 & 0.8 & 1.56 & 2.09 & 0.37 & 4.02 & $\mathrm{~K}$ \\
\hline 0.1 & 0.9 & 1.70 & 2.69 & 0.35 & 4.74 & $\mathrm{~L}$ \\
\hline 0 & 1 & 1.69 & 3.18 & 0.35 & 5.23 & $\mathrm{M}$ \\
\hline
\end{tabular}




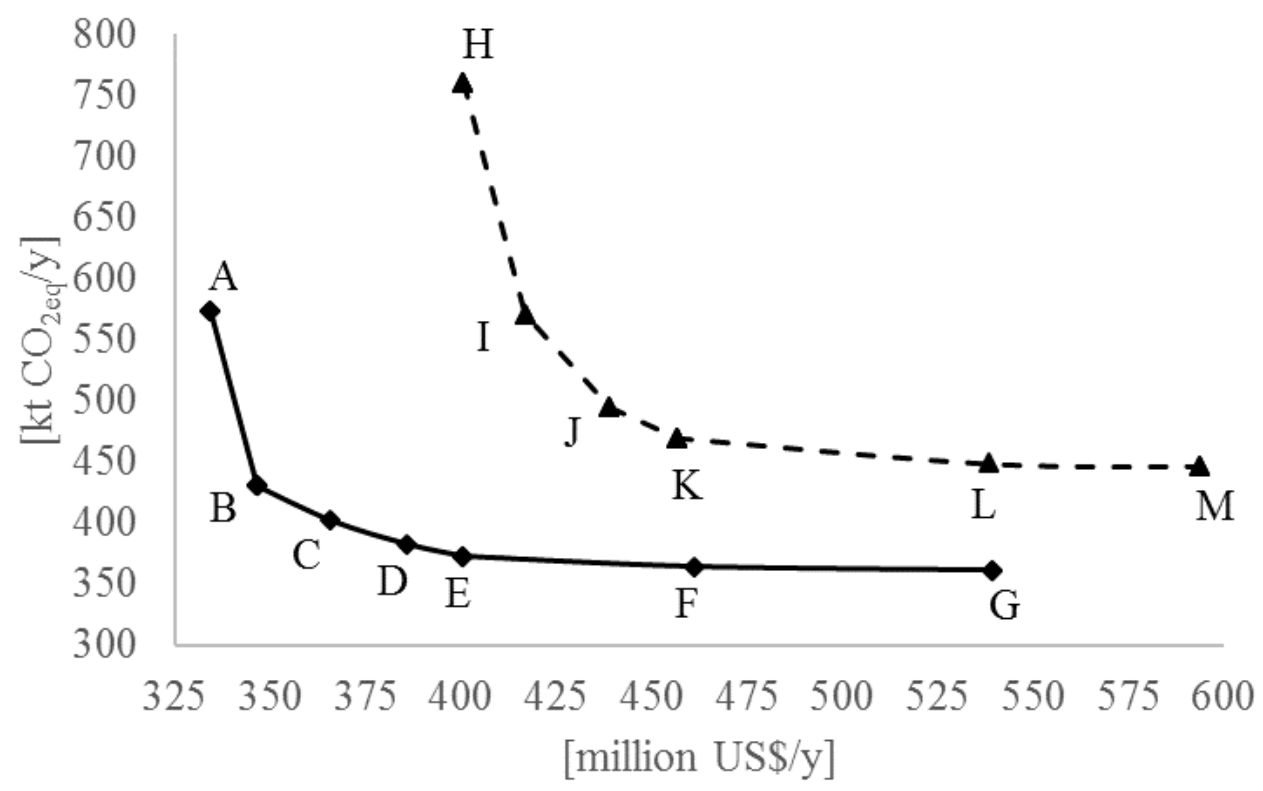

Fig. 6: Case study results (Pareto front)

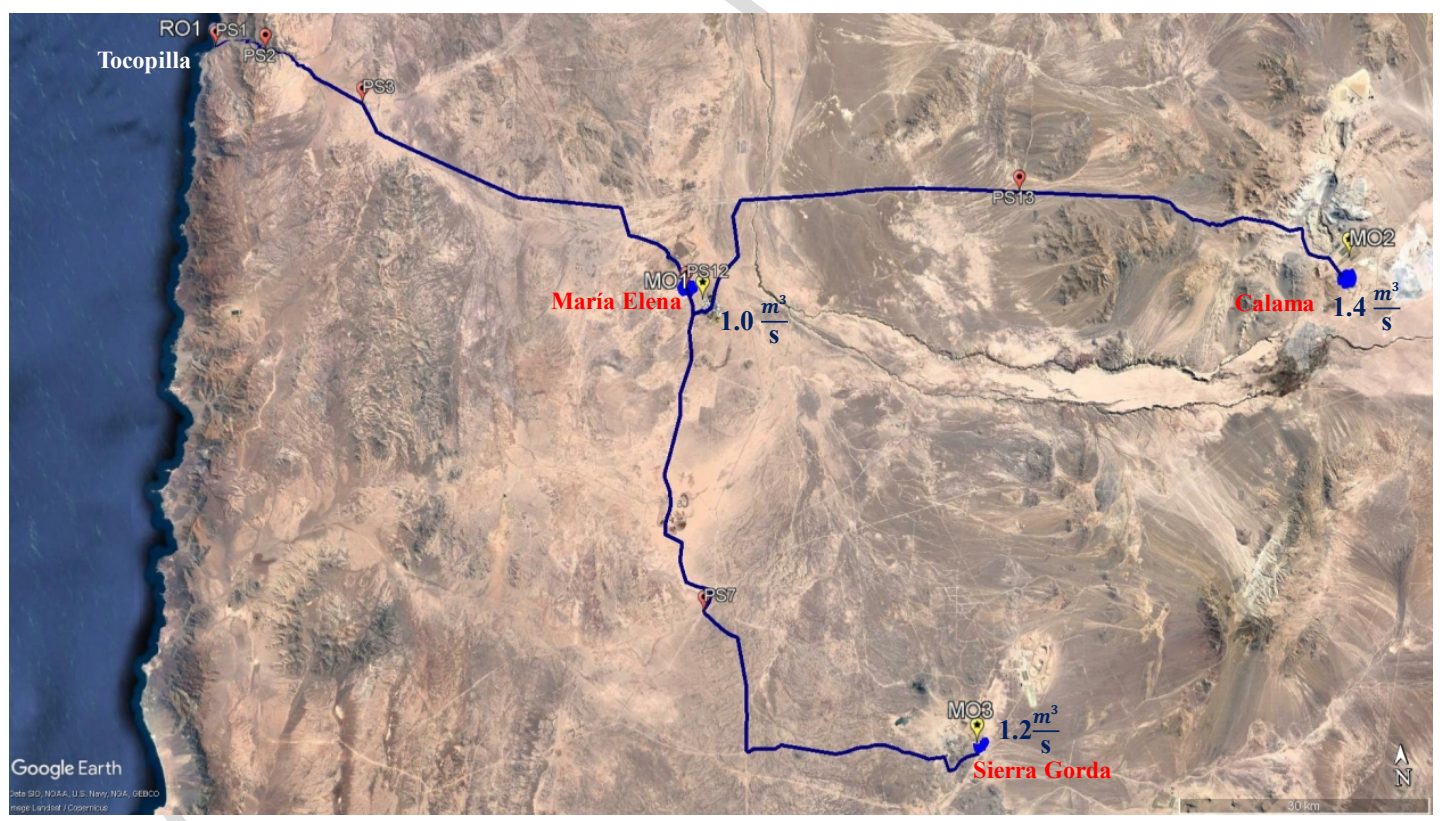

Fig. 7: Integrated water supply system 


\section{Conclusions}

A multi-objective optimization approach is proposed to design and assess an integrated water supply system for the mining industry. The paper discusses the case study of Chile, which considered integrated water demand from three mining operations and the neighboring cities. The main findings have demonstrated that an integrated water supply system is always the best option from an economic and environmental perspective. When economic aspects are a priority, the integrated system is a compact solution with just one desalination plant that meets the demand of all users. Nevertheless, when environmental aspects are a priority, the integrated system becomes large, it encompasses all elements of the network, which allows it to decrease the energy consumption in the system. Moreover, the results indicate that the incorporation of cities generates negative economic and environmental impacts to the system. Nevertheless, if we think of the improvement of human health and the economic and social development, the incorporation of cities generates positive social impacts. Which is in accordance with one of the Sustainable Development Goals declared by the United Nations that seeks to ensure access to water and sanitation for all world population https://www.un.org/sustainabledevelopment/water-andsanitation/. In addition, this aspect could be a significant opportunity for a water company that seeks to create business. Because it is clear that several users would pay and pressure the government to improve regulations in order to establish a safe and continuous access to water. However, the real benefits of this situation and related risks need to be assessed. Results also showed that the incorporation of a PV system, under Chilean circumstances, considerably decreases the GHG emissions from the system and slightly increases its costs. Therefore, the incorporation of a PV system is the best option to create a cleaner system.

\section{Nomenclature}

$\boldsymbol{C}_{\boldsymbol{s o}}^{\boldsymbol{m a x}}:$ maximum production capacity of RO plant $s o\left[\mathrm{~m}^{3} / \mathrm{s}\right]$

$\boldsymbol{C} \boldsymbol{E}$ : electricity supplied by the Chilean power grid $[\mathrm{kWh} / \mathrm{y}]$

$\boldsymbol{C E C N}_{\boldsymbol{n}}$ : annualized capital costs of pumping station $n$ [MUS\$/y]

$\boldsymbol{C} \boldsymbol{E} \boldsymbol{C} \boldsymbol{P}_{n, j}:$ annualized capital cost of pipelines from element $n$ to $j$ [MUSD/y]

$\boldsymbol{C E C S O}_{\text {so }}$ : annualized capital cost of RO plant so [MUS\$/y]

CECSP: annualized capital costs of the PV system [MUS\$/y]

$\boldsymbol{D}_{\boldsymbol{d}}:$ pipe diameter $d[\mathrm{~m}]$

$\boldsymbol{D}_{\boldsymbol{n}, \boldsymbol{j}}:$ pipe diameter selected from node $i$ to $j[\mathrm{~m}]$

$\boldsymbol{d r}$ : discount rate [dimensionless] 
$D Y_{n, j}$ : continuous variable extra for the model $\left[\mathrm{m}^{-5}\right]$

$\boldsymbol{E C}$ : electricity cost [USD/kWh]

$\boldsymbol{E N E}_{\boldsymbol{s o}}$ : annual electricity required by RO plant so $[\mathrm{kWh} / \mathrm{y}]$

$\boldsymbol{E N}_{\boldsymbol{n}}$ : annual electricity required by pumping station $n[\mathrm{kWh} / \mathrm{y}]$

$\boldsymbol{f}$ : Darcy friction factor [dimensionless]

$\boldsymbol{F I X}$ : fixed cost of each RO plant [US $\$ / \mathrm{m}^{3}$ ]

$\boldsymbol{g}$ : gravitational acceleration $\left[\mathrm{m} / \mathrm{s}^{2}\right]$

$\boldsymbol{G} \boldsymbol{H} \boldsymbol{G}$ : annual GHG emissions by system operation $\left[\mathrm{kt} \mathrm{CO}_{2 \mathrm{eq}} / \mathrm{y}\right]$

$\boldsymbol{h}_{\boldsymbol{n}, \boldsymbol{j}}$ : pressure loss in pipelines caused by friction for water flow pumped from node $n$ to $j[\mathrm{~m}]$

$\boldsymbol{H}_{\boldsymbol{n}, j}:$ hydraulic head required in node $n$ to pump water flow to node $j[\mathrm{~m}]$

$\boldsymbol{H}_{\boldsymbol{j}}$ : pressure required in the terminal node $\mathrm{j}[\mathrm{m}]$

IRR: local irradiance $\left(\mathrm{kWh} / \mathrm{m}^{2} \mathrm{~d}\right)$

$\boldsymbol{I R}^{*}$ : irradiance in standard conditions $\left[\mathrm{kWh} / \mathrm{m}^{2}\right]$

$\boldsymbol{L}_{\boldsymbol{n}, j}$ : length of pipeline from node $n$ to $j[\mathrm{~m}]$

MOF: multi-objective function [dimensionless]

$\boldsymbol{O E C N}_{\boldsymbol{n}}$ : operational cost of pumping station $n$ [MUS\$/y]

OECSO $_{\text {so }}$ : operational cost of RO plant so [MUS\$/y]

OECSP: operational cost of the PV system [MUS\$/y]

$\boldsymbol{P}_{\boldsymbol{n}}$ : power required by pumping station $n[\mathrm{~kW}]$

$\boldsymbol{P P}$ : PV system capacity in standard conditions [kW]

$\boldsymbol{P} \boldsymbol{R}$ : performance ratio [dimensionless]

$\boldsymbol{Q}_{\boldsymbol{i}, j}$ : water flow pumped from node $i$ to $j\left[\mathrm{~m}^{3} / \mathrm{s}\right]$

$\boldsymbol{Q}_{\boldsymbol{s i}}$ : water flow delivered to mining operation $s i\left[\mathrm{~m}^{3} / \mathrm{s}\right]$

$\boldsymbol{Q}_{\text {so }}$ : water flow produced by RO plant so $\left[\mathrm{m}^{3} / \mathrm{s}\right]$

$\boldsymbol{R}_{\boldsymbol{s i}}:$ water flow required for mining operation $s i\left[\mathrm{~m}^{3} / \mathrm{s}\right]$

$\boldsymbol{S E}$ : electricity supplied by the PV system $[\mathrm{kWh} / \mathrm{y}]$

$\boldsymbol{T}$ : quantity of hours per year that system is operating $[\mathrm{h} / \mathrm{y}]$

TC: total cost of the system [MUS $\$ / y$ ]

$\boldsymbol{T} \boldsymbol{E}$ : total annual electricity required by the water supply system $[\mathrm{kWh} / \mathrm{y}]$

TT: quantity of days per year that system is operating [d/y]

$\boldsymbol{U N C}$ : unitary electrical energy consumption of each RO plant $\left[\mathrm{kWh} / \mathrm{m}^{3}\right]$

$\boldsymbol{U N C ^ { * }}$ : modified unitary electrical energy consumption of each RO plant $\left[\mathrm{kWs} / \mathrm{m}^{3}\right]$

$\boldsymbol{U} \boldsymbol{N E}$ : unitary GHG emissions by the Chilean power grid $\left[\mathrm{kt} \mathrm{CO}_{2 \mathrm{eq}} / \mathrm{kWh}\right]$

UNESP: unitary GHG emissions by the PV system[ $\left[\mathrm{kt} \mathrm{CO}_{2 \mathrm{eq}} / \mathrm{kWh}\right]$

$v^{\max }$ : maximum linear velocity of water flow into pipelines $[\mathrm{m} / \mathrm{s}]$

$\boldsymbol{w}_{\mathbf{1}}$ : weight for economic aspect [dimensionless]

$\boldsymbol{w}_{2}$ : weight for environmental aspect [dimensionless] 
$\boldsymbol{y}_{\boldsymbol{n}, \boldsymbol{j}, \boldsymbol{d}}$ : binary variable to select pipe diameter $d$ for pipeline from node $i$ to $j$ [dimensionless]

$\boldsymbol{y}_{\boldsymbol{n}, \boldsymbol{j}}$ : binary variable to select the existence of pipelines from node $i$ to $j$ [dimensionless]

year: investment period $[\mathrm{y}]$

$\Delta \boldsymbol{Z}_{\boldsymbol{i}, \boldsymbol{j}}:$ altitude difference between node $i$ and $j[\mathrm{~m}]$

$\boldsymbol{\eta}$ : combined efficiency of the pump and prime mover [dimensionless)]

$\boldsymbol{\rho}$ : mass density of water $\left[\mathrm{kg} / \mathrm{m}^{3}\right]$

\section{Acknowledgments}

The authors thanks to CICITEM for their funding through the project R15A10002.

\section{References}

Aitken, D., Rivera, D., Godoy-Faúndez, A. and Holzapfel, E., 2016. Water scarcity and the impact of the mining and agricultural sectors in Chile. Sustainability, 8(2), p.128.

Chilean Copper Commission, 2013. Mining in Chile: Impact on Regions and Challenges for its Development (Minería en Chile: Impacto en Regiones y Desafíos para su Desarrollo). Ministerio de Minería, Chile.

Chilean Copper Commission, 2016a. Water consumption in copper mining by 2016 (Consumo del agua en la minería del cobre al 2016). Ministerio de Minería, Chile.

Chilean Copper Commission, 2016b. Projection of water consumption in copper mining 20162027 (Proyección de consumo de agua en la minería del cobre 2016-2027). Ministerio de Minería, Chile.

Chilean National Energy Commission, 2015. Energy Statistical Yearbook Chile. Ministerio de Energía, Chile.

Chilean National Productivity Commission, 2017. Productivity in the Great Copper Mining (Productividad en la Gran Minería del Cobre). Chile.

Cisternas, L.A. and Gálvez, E.D., 2014. Chile’s mining and chemicals industries. Chem. Eng. Prog, 110, pp.46-51.

Cisternas, L.A. and Gálvez, E.D., 2018. The use of seawater in mining. Mineral Processing and Extractive Metallurgy Review, 39(1), pp.18-33.

Chenoweth, J., 2008. Minimum water requirement for social and economic development. Desalination, 229(1-3), pp.245-256.

Clarke, J.D., 2006. Antiquity of aridity in the Chilean Atacama Desert. Geomorphology, 73(1), pp.101-114.

Côte, C.M., Moran, C.J., Hedemann, C.J. and Koch, C., 2010. Systems modelling for effective mine water management. Environmental Modelling \& Software, 25(12), pp.1664-1671.

Dixon, R.E., 2013. Northern Chile and Peru: a hotspot for desalination. Desalination and Water Treatment, 51(1-3), pp.5-10. 
Fuentealba, E., Ferrada, P., Araya, F., Marzo, A., Parrado, C. and Portillo, C., 2015. Photovoltaic performance and LCoE comparison at the coastal zone of the Atacama Desert, Chile. Energy Conversion and Management, 95, pp.181-186.

Gao, L., Barrett, D., Chen, Y., Zhou, M., Cuddy, S., Paydar, Z. and Renzullo, L., 2014. A systems model combining process-based simulation and multi-objective optimisation for strategic management of mine water. Environmental modelling \& software, 60, pp.250-264.

Gao, L., Bryan, B.A., Liu, J., Li, W., Chen, Y., Liu, R. and Barrett, D., 2017. Managing too little and too much water: robust mine-water management strategies under variable climate and mine conditions. Journal of cleaner production, 162, pp.1009-1020.

Gao, L., Hou, C., Chen, Y., Barrett, D., Mallants, D., Li, W. and Liu, R., 2016. Potential for mine water sharing to reduce unregulated discharge. Journal of Cleaner Production, 131, pp.133144.

GAMS, 2014. GAMS Development Corporation. GAMS, Washington, DC, USA.

Ghaffour, N., Missimer, T.M. and Amy, G.L., 2013. Technical review and evaluation of the economics of water desalination: current and future challenges for better water supply sustainability. Desalination, 309, pp.197-207.

Gunson, A.J., Klein, B., Veiga, M. and Dunbar, S., 2010. Reducing mine water network energy requirements. Journal of Cleaner Production, 18(13), pp.1328-1338.

Gunson, A.J., Klein, B., Veiga, M. and Dunbar, S., 2012. Reducing mine water requirements. Journal of Cleaner Production, 21(1), pp.71-82.

Ghorbani, Y. and Kuan, S.H., 2017. A review of sustainable development in the Chilean mining sector: past, present and future. International Journal of Mining, Reclamation and Environment, 31(2), pp.137-165.

Gude, V.G., 2016. Desalination and sustainability-an appraisal and current perspective. Water research, 89, pp.87-106.

Haas, J., Palma-Behnke, R., Valencia, F., Araya, P., Díaz-Ferrán, G., Telsnig, T., Eltrop, L., Díaz, M., Püschel, S., Grandel, M. and Román, R., 2018. Sunset or sunrise? Understanding the barriers and options for the massive deployment of solar technologies in Chile. Energy Policy, 112, pp.399-414.

Herrera, S., Cisternas, L.A, and Galvéz, E.D., 2015. Simultaneous design of desalinatation plants and distribution water network. . Computer Aided Chemical Engineering, 37, pp.11931198.

Herrera-León, S., Lucay, F., Kraslawski, A., Cisternas, L.A. and Gálvez, E.D., 2018. Optimization Approach to Designing Water Supply Systems in Non-Coastal Areas Suffering from Water Scarcity. Water Resources Management, 32(7), pp.2457-2473.

International Renewable Energy Agency, 2018. Renewable Power Generation Costs in 2017. IRENA, Abu Dhabi.

Ihle, C.F. and Kracht, W., 2018. The relevance of water recirculation in large scale mineral processing plants with a remote water supply. Journal of Cleaner Production, 177, pp.3451. 
Jakob, W. and Blume, C., 2014. Pareto optimization or cascaded weighted sum: A comparison of concepts. Algorithms, 7(1), pp.166-185.

Jeldres, R.I., Forbes, L. and Cisternas, L.A., 2016. Effect of seawater on sulfide ore flotation: a review. Mineral Processing and Extractive Metallurgy Review, 37(6), pp.369-384.

Joo, Y.J., Kim, C.S. and Yoo, S.H., 2015. Energy consumption, $\mathrm{CO}_{2}$ emission, and economic growth: Evidence from Chile. International journal of green energy, 12(5), pp.543-550.

Kunz, N.C. and Moran, C.J., 2014. Sharing the benefits from water as a new approach to regional water targets for mining companies. Journal of cleaner production, 84, pp.469-474.

Kunz, N.C., Moran, C.J. and Kastelle, T., 2013. Implementing an integrated approach to water management by matching problem complexity with management responses: a case study of a mine site water committee. Journal of cleaner production, 52, pp.362-373.

Marler, R.T. and Arora, J.S., 2005. Function-transformation methods for multi-objective optimization. Engineering Optimization, 37(6), pp.551-570.

Marler, R.T. and Arora, J.S., 2010. The weighted sum method for multi-objective optimization: new insights. Structural and multidisciplinary optimization, 41(6), pp.853-862.

Meza, F.J., Vicuna, S., Gironás, J., Poblete, D., Suárez, F. and Oertel, M., 2015. Water-foodenergy nexus in Chile: the challenges due to global change in different regional contexts. Water International, 40(5-6), pp.839-855.

Moreno, P.A., Aral, H., Cuevas, J., Monardes, A., Adaro, M., Norgate, T. and Bruckard, W., 2011. The use of seawater as process water at Las Luces copper-molybdenum beneficiation plant in Taltal (Chile). Minerals Engineering, 24(8), pp.852-858.

Moreno-Leiva, S., Díaz-Ferrán, G., Haas, J., Telsnig, T., Díaz-Alvarado, F.A., Palma-Behnke, R., Kracht, W., Román, R., Chudinzow, D. and Eltrop, L., 2017. Towards solar power supply for copper production in Chile: Assessment of global warming potential using a life-cycle approach. Journal of Cleaner Production, 164, pp.242-249.

Northey, S.A., Mudd, G.M., Saarivuori, E., Wessman-Jääskeläinen, H. and Haque, N., 2016. Water footprinting and mining: Where are the limitations and opportunities?. Journal of Cleaner Production, 135, pp.1098-1116.

Lagos, G., Peters, D., Videla, A. and Jara, J.J., 2018. The effect of mine aging on the evolution of environmental footprint indicators in the Chilean copper mining industry 20012015. Journal of Cleaner Production, 174, pp.389-400.

Lin, M.H., Carlsson, J.G., Ge, D., Shi, J. and Tsai, J.F., 2013. A Review of Piecewise Linearization Methods. Mathematical Problems in Engineering.

Liu, W., Moran, C.J. and Vink, S., 2013. A review of the effect of water quality on flotation. Minerals Engineering, 53, pp.91-100

Pamparana, G., Kracht, W., Haas, J., Díaz-Ferrán, G., Palma-Behnke, R. and Román, R., 2017. Integrating photovoltaic solar energy and a battery energy storage system to operate a semiautogenous grinding mill. Journal of Cleaner Production, 165, pp.273-280. 
Rivera, D., Godoy-Faúndez, A., Lillo, M., Alvez, A., Delgado, V., Gonzalo-Martin, C., Menasalvas, E., Costumero, R. and Garcia-Pedrero, A., 2016. Legal disputes as a proxy for regional conflicts over water rights in Chile. Journal of Hydrology, 535, pp.36-45.

Samra, S., Abood, M., 2014. NSW Reference Rates Manual - Valuation of Water Supply, Sewerage and Stormwater Assets. Department of Primary Industries, a division of NSW Department of Trade and Investment, Regional Infrastructure and Services, Australia.

Shahabi, M.P., McHugh, A., Anda, M. and Ho, G., 2017. A framework for planning sustainable seawater desalination water supply. Science of The Total Environment, 575, pp.826-835.

Shen, L., Tam, V.W., Gan, L., Ye, K. and Zhao, Z., 2016. Improving sustainability performance for public-private-partnership (PPP) projects. Sustainability, 8(3), p.289.

Shrestha, E., Ahmad, S., Johnson, W., Shrestha, P. and Batista, J.R., 2011. Carbon footprint of water conveyance versus desalination as alternatives to expand water supply. Desalination, 280(1-3), pp.33-43.

Swamee P.K and Sharma A.K., 2008. Design of water supply pipe networks. Wiley, New York.

Urkidi, L., 2010. A glocal environmental movement against gold mining: Pascua-Lama in Chile. Ecological Economics, 70(2), pp.219-227.

Valdés-Pineda, R., Pizarro, R., García-Chevesich, P., Valdés, J.B., Olivares, C., Vera, M., Balocchi, F., Pérez, F., Vallejos, C., Fuentes, R. and Abarza, A., 2014. Water governance in Chile: Availability, management and climate change. Journal of Hydrology, 519, pp.2538-2567.

Wessman, H., Salmi, O., Kohl, J., Kinnunen, P., Saarivuori, E. and Mroueh, U.M., 2014. Water and society: mutual challenges for eco-efficient and socially acceptable mining in Finland. Journal of cleaner production, 84, pp.289-298.

Zhang, A., Moffat, K., Lacey, J., Wang, J., González, R., Uribe, K., Cui, L. and Dai, Y., 2015. Understanding the social licence to operate of mining at the national scale: a comparative study of Australia, China and Chile. Journal of Cleaner Production, 108, pp.1063-1072.

Zhou, Y. and Tol, R.S., 2005. Evaluating the costs of desalination and water transport. Water resources research, 41(3). 
- A new optimization approach to designing integrated water supply systems is presented

- The trade-off between economic and environmental aspects of the system is assessed

- The results show that an integrated system is always the best option 